\title{
MEDIA PEMBELAJARAN DALAM PENDIDIKAN MATEMATIKA
}

Oleh

\section{Muhammad Lutfil Hakim}

\section{Lutfiy.brown@gmail.com}

\begin{abstract}
Abstrak
Salah satu cara untuk membantu dalam proses belajar mengajar adalah media pembelajaran. Dengan adanya pembelajaran, baik pendidik maupun peserta didik dapat meningkatkan efesienitas dan efektifitas pada saat proses pembelajaran berlangsung. Peranan media pembelajaran sendiri sangat krusial di dalam proses pembelajaran bahkan pensil dan penggaris juga termasuk dalam media pembelajaran. Di zaman modern dengan kemajuan teknologi yang begitu pesat media pembelajaran tradisional mulai diambil alih perannya oleh media pembelajaran yang modern.
\end{abstract}

\section{A. LATAR BELAKANG}

Pada saat proses pembelajaran berlangsung, metode mengajar dan media pembelajaran sangat berperan penting. Makalah ini akan membahas mengenai media pembelajaran dalam pendidikan matematika. Kita Ketahui, banyaknya macam media pembelajaran. Untuk itu seorang pendidik harus mampu memilih media yang tepat yang sesuai dengan materi yang akan diajarkan. Matematika merupakan salah satu mata pelajaran wajib pada jenjang sekolah dasar, sekolah menengah pertama dan sekolah menengah atas. Pembelajaran matematika membutuhkan interaksi antara guru dan siswa serta antarsiswa untuk menyelesaikan sebuah masalah matematika. Suatu proses belajar mengajar akan menjadi efektif jika para pembelajar saling mengkomunikasikan ide melalui interaksi sosial. Pembelajaran.(Irmayanti et al., 2020)

Menurut (Harjanto ,1997) Jika ditinjau lebih dalam tentang media pembelajaran, hal yang lebih penting yaitu terwujudnya tujuan yang diharapkan adalah penggunaan media ketika proses pembelajaran berlangsung. Apabila hal ini terwujud maka akan menimbulkan suatu proses pembelajaran yang efektif dan efisien. Ada berbagai faktor yang harus di rubah dan dikembangkan dalam dunia pendidikan dan pengajaran, salah satu faktor yang tersebut adalah perubahan dan pengembangan serta pemakaian media pembelajaran dalam mendidik dan mengajar. Agar proses belajar mengajar berjalan dengan baik kita harus menggunakan media pembelajaran yang tepat. Dalam memilih media pembelajaran kita perlu berpikir kreatif, 
berpikir kreatif membutuhkan suatu konteks dimana individu melakukan persiapan yang didasarkan pada pengalaman-pengalaman sebelumnya (Nurjannah, 2020). Misalnya dalam pemilihan media pembelajaran mengenai konsep pecahan, penyelesaian soal operasi hitung bilangan pecahan membutuhkan pemahaman konsep yang lebih sulit dibandingkan dengan operasi hitung bilangan lainnya, sehingga banyak siswa yang mengalami kesulitan dalam memahami operasi hitung bilangan pecahan berdasarkan(Mytra \& Heriyanti, 2000).

\section{B. RUMUSAN MASALAH}

1. Apakah yang dimaksud dengan media pembelajaran ?

2. Apa sajakah jenis-jenis media pembelajaran ?

3. Apakah manfaat dari media pembelajaran ?

4. Apa sajakah kriteria yang perlu diperhatikan dalam pemilihan media pembelajaran matematika?.

5. Bagaimanakah prinsip-prinsip dalam pemilihan media pembelajaran ?

6. Apa kelebihan dan kekurangan dari jenis-jenis media yang digunakan?

7. Bagaimana menerapkan media ke dalam pembelajaran matematika?

C. TUJUAN

1. Untuk mengetahui definisi dari media pembelajaran.

2. Untuk mengetahui jenis-jenis media pembelajaran.

3. Untuk mengetahui manfaat dari media pembelajaran.

4. Untuk mengetahui alasan-alasan penggunaan media dalam proses pembelajaran.

\section{A. PENGERTIAN MEDIA PEMBELAJARAN}

Kata media berasal dari bahasa Latin yaitu medio. Dalam bahasa Latin, media dimaknai sebagai antara. Media merupakan bentuk jamak dari medium, yang secara harfiah berarti perantara atau pengantar. Secara khusus, kata tersebut dapat diartikan sebagai alat komunikasi yang digunakan untuk membawa informasi dari satu sumber kepada penerima. Media pembelajaran adalah bahan, alat, atau teknik yang digunakan dalam kegiatan belajar mengajar dengan maksud agar proses interaksi komunikasi edukasi antara guru dan siswa dapat berlangsung secara tepat guna dan berdaya guna (Sadiman ,2002:6). Media pembelajaran 
memanglah tidak bisa lepas dari proses pembelajaran baik dalam pendidikan formal maupun informal. Dari uraian teks sebelumnya, maka dapat disimpulkan bahwa media pembelajaran segala sesuatu yang bisa digunakan pada saat pembelajaran berlangsung.

\section{B. JENIS - JENIS MEDIA PEMBELAJARAN}

Dalam bukunya tentang jenis-jenis media pembelajaran, (Bahri Djamarah \& Aswan Zain ,2006) Mengatakan media pembelajaran dibagi 7 kelompok, yaitu :

\section{Media Grafis, Bahan Cetak dan Gambar Diam}

Media grafis, yaitu gambar visual yang menyajikan fakta, gagasan, atau gagasan dengan menampilkan kata, kalimat, angka, dan simbol / gambar. Grafik biasanya digunakan untuk menarik perhatian orang, memperjelas cara berpikir dan menjelaskan fakta, sehingga orang menjadi menarik dan diingat. Konten yang memuat media grafik antara lain grafik, bagan, diagram, sketsa, poster, panel flanel dan papan buletin. Media bahan cetak merupakan media visual yang dihasilkan melalui proses pencetakan atau cetak offset.

Materi cetakan menampilkan informasinya melalui teks dan gambar untuk lebih memperjelas informasi atau informasi yang ditampilkan. Jenis media bahan cetakan antara lain buku teks, modul, dan bahan pemrograman. Media citra diam merupakan salah satu jenis media visual yang berupa citra yang dihasilkan melalui proses fotografis, sedangkan jenis medianya adalah citra.

\section{Media Proyeksi Diam}

Media proyeksi diam adalah media visual yang diproyeksikan atau media proyeksi pesan, di mana proyeksinya tidak bergerak atau bergerak sangat sedikit. Ada beberapa jenis media ini:

a. Media OHP/OHT. OHT (Overhead Transparency) adalah media visual yang diproyeksikan oleh alat proyeksi. Media OHP (Proyektor). Ini adalah media yang digunakan untuk memproyeksikan program transparansi di layar. Biasanya alat ini digunakan untuk menggantikan papan tulis. Media Opaque Projector (proyektor tak tembus pandang) dalah media yang digunakan untuk memproyeksikan bahan dan 
benda-benda yang tidak tembus pandang, seperti buku, foto dan model-model baik yang dua dimensi maupun yang tiga dimensi. Berbeda dengan OHP,Opaque projector ini tak memerlukan transparansi, tapi memerlukan penggelapan ruangan.

b. Media Slide atau Film Bingkai adalah media visual yang diproyeksikan melaluialat yang disebut proyektor slide. Slide atau film bingkai terbuat dari film positif yang kemudian diberi bingkai yang terbuat dari karton atau plastik. Film strip ini terdiri atas beberapa film yang merupakan satu kesatuan.

\section{Media Audio}

Media audio adalah media yang penyampaian pesannya hanya dapat diterima oleh indera pendengaran. Pesan atau nformasi yang akan disampaikan dituangkan ke dalam lambang-lambang auditif yang berupa kata-kata, musik dan sound effect. Media Radio yaitu media audio yang penyampaian pesannya dilakukan melalui pencaran Gelombang elektromagnetik dari suatu pemancar.

Pemberi pesan (penyiar) secara langsung dapat mengkomunikasikan pesan atau informasi melalui suatu alat (microfon) yang kemudian diolah dan dipancarkan ke segenap penjuru melalui gelombang elektromagnetik dan penerima pesan (pendengar) menerima pesan atau informasi tersebut dari pesawat radio di rumah-rumah atau para siswa mendengarkannya di kelas-kelas. Media Alat Perekam Pita Magnetik adalah media yang menyajikan pesan melalui proses perekam kaset audio.

\section{Media Audio Visual Diam}

Media audio visual diam adalah media dalam menyampaikan pesannya bisa diterima dicerna indera pendengaran dan juaga penglihatan. meskipun bisa dilihat, gambarnyapun tidak terlalu banyak bergerak bahkan bisa saja tidak bergerak. Dalam penerapannya antara lain slide suara, film dengan menampilkan warna dengan bersuara, dan field sound.

\section{Film (Motion Pictures)}

Film (motion pictures) yaitu tersusun dari berbagai gambar yang terurut dari sepersekian detik hingga bisa terlihat seperti terlihat sesuatu yang bergerak. dalam film biasanya terdapat suara ataupun backsound maupun soundtrack. Dalam film dikenal 
dengan adanya fps atau framepersecond, yaitu banyaknya frame (gambar) dari 1 detik durasi meski rata - rata film memiliki frame sebanyak 30 fps dan ada juga 60 fps.

\section{Televisi}

Televisi sendiri terdiri dari tranmiter dan juga recevier. Televisi merupakan media yang sudah ada dan memang menjadi media untuk menyampaikan informasi dari berbagai genre. Salah satunya adalah pendidikan, seperti menyampaikan manfaatnya menggosok gigi sesudah makan dan sebelum tidur.

\section{Multimedia}

Dikenal sebagai suatu sistem penyimpaian dan bisa digunakan untuk berbagai jenis bahan belajar yang membentuk suatu kesatuan paket. Dari berbagai macam barang multimedia sekarang, tentu saja seorang guru harus cakap dalam menggunakan guna membantu peserta didik dalam memahami pelajaran yang diberikan. Harapan besar dengan berbagai macam media yang bisa digunakan dapat memancing ketertarikan siswa hingga mau ikut terlibat dan aktif dan proses belajar mengajar. Menurut Bahri Djamarah dan Aswan Zain (2006) dilihat dari jenisnya, media terbagi menjadi:

a. Media Auditif, media dengan output sebagai sebuah suara saja. seperi radio, kaset rekoorder, piringan hitam. Sehingga media ini tidak cocok untuk tunarungu.

b. Media Visual, media dengan output yang bisa ditangkap indera mata. Pada penggunaan media ini ada yang menampilkan gambar diam seperti film strip, slides, foto, gambar atau lukisan, dan cetakan. Disamping itu ada pula yang menampilkan gambar atau simbol yang dapat bergerak seperti film bisu charlie chaplin, dan film kartun.

c. Media Audio Visual, dan merupakan media yang mempunyai 2 unsur yaitu unsur suara dan unsur gambar. Kemampuan dari jenis media ini lebih baik karena gabungan dari beberapa media sebelumnya. Media ini dibagi dalam:

1.) Audio visual murni, baik unsur suara maupun unsur gambar berasal dari satu sumber perekaman seperti video kaset. 
2.) Audio visual tidak murni, unsur suara dan unsur gambarnya berasal dari sumber yang berbeda. Misalnya film bingkai suara yang unsur gambarnya berasal dari slide proyektor.

Dari uraian diatas, dapat disiimpulkan secara garis besar media pembelajaran dibagi menjadi tiga yaitu Media Audio (didengar), Media Visual (dilihat) dan Media Audivoisual (lihat dan dengar). Media pembelajaran dapat di kategorikan sebagai berikut:

\section{NON PROJECTED}
a. Flannel Board
b. Sketsa/Poster/Gambar
c. Flip Chart
d. Metaplan
e. Mesin/Peralatan
f. Kartu

\section{PROJECTED}
a. Papan Tulis Elektronik
b. Opaque Projector
c. Overhead Projector
d. Slide
e. LCD Projector

3. AUDIO
a. Radio
b. Tape Recording
c. CD Recording, CD Audio
d. Language Lab System
e. Sound System
f. Piringan Hitam

\section{PROJECTED AUDIO VISUAL}
a. TV
b. Film Strip
c. Video Clip 

d. In-focus/LCD Projector + Audio
e. Slide + Sound System
f. Tele Conferencing
g. Distance Lecturing

C. Manfaat Media Pembelajaran.

Menurut (Sudjana \& et al., 2007) manfaat penggunaan media pengajaran dalam kegiatan belajar mengajar, yaitu :

1. Media pengajaran dapat menarik dan memperbesar perhatian anak didik terhadap materi pengajaran yang disajikan,

2. Media pengajaran dapat mengatasi perbedaan pengalaman belajar anak didik berdasarkan latar belakang sosial ekonomi,

3. Media pengajaran dapat membantu anak didik dalam memberikan pengalaman belajar yang sulit diperoleh dengan cara lain,

4. Media pengajaran dapat membantu perkembangan pikiran anak didik secara teratur tentang hal yang mereka alami dalam kegiatan belajar mengajar mereka, misalnya menyaksikan pemutaran film tentang suatu kejadian atau peristiwa. Rangkaian dan urutan kejadian yang mereka saksikan dan pemutaran film tadi akan dapat mereka pelajari secara teratur dan berkesinambungan,

5. Media pengajaran dapat menumbuhkan kemampuan anak didik untuk berusaha mempelajari sendiri berdasarkan pengalaman dan kenyataan,

6. Media pengajaran dapat mengurangi adanya verbalisme dalam suatu proses (dalam bentuk kata-kata tertulis atau lisan belaka).

\section{KRITERIA PEMILIHAN MEDIA PEMBELAJARAN}

Menurut (Nana \& Sudjana ,2007) Kriteria khusus dalam memilih pembelajaran yang tepat dirumuskan dalam kata ACTION, yaitu :

1. Acces, kemudahan akses menjadi pertimbangan pertama dalam memilih media. Apakah media yang kita perlukan itu tersedia, mudah dan dapat dimanfaatkan oleh pesrta didik atau tidak. 
2. Cost, biaya juga harus dipertimbangkan. Media efektif tidak selalu mahal jika guru kreatif dan menguasai betul materi pelajaran maka akan memanfaatkan objek-objek untuk dijadikan sebagai media dengan biaya yang murah tapi efektif.

3. Technology, teknologi juga harus diperhatikan apakah teknologinya tersedia dan mudah menggunakannya.

4. Interactivity, media yang baik adalah media yang dapat memunculkan komunikasi 2 arah.

5. Organization, diperlukan dukungan organisasi misalnya pimpinan sekolah.

6. Novelty, media yang lebih baru biasanya lebih baik danl ebih menarik bagi siswa.

Dari uraian ACTION diatas, bisa disimpulkan dimana kemudahan akses sangat diperlukan, biaya yang harus disesuikan dengan pengadaan media yang efektif, penggunaan teknologi terbaru juga diperlukan agar tidak ketinggalan zaman, media yang digunakan bisa memunculkan komunikasi saat pembelajaran, dukungan dari badan terkait juga sangat perlu agar tidak terjadi pelanggaran hukum atau menyalahi aturan sekolah, dan terakhir tentu saja harus ada pembaruan dari media yang sebelumnya pernah digunakan. Apalagi di zaman serba canggih sekarang tidak sulit untuk mencari media yang dapat membantu keefektifitan pada proses belajar mengajar berlangsung.

\section{E. PRINSIP-PRINSIP PEMILIHAN MEDIA PEMBELAJARAN}

Beberapa pedoman yang dapat digunakan untuk memilih media pembelajaran, antara lain (Netriwati \& Lena, 2019) :

1. Sebelum memilih media pembelajaran, guru harus menyadari bahwa tidak ada satupun media yang paling baik untuk mencapai semua tujuan. Penggunaan berbagai macam media pembelaiaran yang disusun secara serasi dalam proses belajar mengajar akan mengefektifkan pencapaian tujuan pembelajaran,

2. Pemilihan media hendaknya dilakukan secara objektif, artinya benar-benar digunakan dengan dasar pertimbangan efektivitas belajar siswa, bukan karena kesenangan guru atau sekedar sebagai selingan,

3. Pemilihan media hendaknya memperhatikan syarat-syarat
a. Sesuai dengan tujuan pembelajaran yang akan dicapai.
b. Ketersediaan bahan media.
c. Biaya pengadaan
d. Kualitas atau mutu teknik. 


\section{F. KELEBIHAN DAN KEKURANGAN JENIS-JENIS MEDIA PEMBELAJARAN}

1. Media Visual(Netriwati \& Lena, 2019)

Macam- macam Media Visual adalah sebagai berikut:

a. Media yang tidak diproyeksikan.

b. Media realita adalah benda nyata.

c. Model,

d. Media grafi.

Adapun kelebihan media visual adalah sebagai berikut:

a. Repeatable, dapat dibaca berkali-kali dengan menyimpannya atau mengelipingnya.

b. Analisa lebih tajam,dapat membuat orang benar- benar mengerti isi berita dengan analisa yng lebih mendalam dan dapt membuat orang berfikir lebih spesifik tentang isi tulisan.

Kekurangan media visual :

a. Lambat, dan kurang praktis

b. Kurang mendetail materi yang disampaikan.

c. Visual yang terbatas, media ini hanya dapat memberikan visual berupa gambar yang mewakili isi berita.

d. Produksi, biaya produksi cukup mahal karena media cetak harus menyetak dan mengirimkannya sebelum dapat dinikmati oleh masyarakat.

2. Media Audio

Media berupa audio, yaitu suatu alat yang dapat ditangkap melalui alat pendengaran. Beberapa bentuk media audio antaralain, radio dan kaset.

Kelebihan Media Audio menurut pendapat (Sadiman ,2005 : 50):

a. Harga murah dan variasi program lebih banyak dari pada TV.

b. Sifatnya mudah untuk dipindahkan.

c. Dapat digunakan bersama - sama dengan alat perekam radio, sehingga dapat diulang atau diputar kembali.

d. Dapat merangsang partisifasi aktif pendengaran siswa, serta dapat mengembangkan daya imajinasi seperti menulis, menggambar dan sebagainya. 
e. Dapat memusatkan perhatian siswa seperti membaca puisi, sastra, menggambar musik dan bahasa.

Kekurangan Media Audio menurut (Rivai ,2005 : 131):

a. Memerlukan suatu pemusatan pada suatu pengalaman yang tetap dan tertentu, sehingga pengertiannya harus didapat dengan cara belajar khusus.

b. Media Audio yang menampilkan symbol digit dan analog dalam bentuk auditif adalah abstrak, sehingga pada hal - hal tertentu memerlukan bantuan pengalaman visual.

c. Karena abstrak, tingkatan pengertiannya hanya bisa dikontrol melalui tingkatan penguasaan pembendaharaan kata - kata atau bahasa, serta susunan kalimat.

d. Media ini hanya akan mampu melayani secara baik bagi mereka yang sudah mempunyai kemampuan dalam berfikir abstrak.

e. Penampilan melalui ungkapan perasaan atau symbol analog lainnya dalam bentuk suara harus disertai dengan perbendaharaan pengalaman analog tersebut pada si penerima. Bila tidak bisa maka akan terjadi kesalahpahaman.

3. Media Audio Visual

Adapun contoh media audio visual, diantaranya:

a. Film Suara

b. Video / VCD

c. Film Televisi

d. Media Pembelajaran Berbasis Komputer

e. CD Multimedia Interaktif

f. Internet

g. Pemanfaatan Internet Sebagai Media Pembelajaran

Syaiful Bahri Djamarah mengemukakan bahwa, adapun keuntungan menggunakan media audio visual diantaranya :

a. Menarik perhatian dan memotivasi siswa untuk mempelajari materi lebih banyak.

b. Mengembangkan keterampilan mendengar dan mengevaluasi apa yang telah didengar. 
c. Mengatur dan mempersiapkan diskusi atau debat dengan mengungkapkan pendapat - pendapat dan membuat peserta didik berfikir dan berinovasi dalam menyampaikan pendapat.

d. Menjadikan model yang akan ditiru oleh siswa.

e. Menyiapkan variasi yang menarik dan perubahan - perubahan tingkat kecepatan belajar mengenai suatu pokok pembahasan atau suatu permasalahan.

f. Metode megajar akan lebih bervariasi tidak semata-mata komunikasi verbal melalui penuturan kata-kata sehingga siswa tidak bosan dalam setiap jam pelajaran.

g. Mengukur kemampuan siswa memperoleh informasi dan pemahaman melalui materi audio visual.

Syaiful Bahri Djamarah mengemukakan bahwa, adapun kekurangan dalam penggunaan audio visual, diantaranya:

a. Memerlukan berbagai fasilitas peralatan dan bahan yang tidak selalu mudah diperoleh dan mahal.

b. Banyak memakan waktu baik waktu persiapan dalam rangka pemahaman isi bahan pelajaran maupun pada pelaksanaan pembelajaran.

c. Apabila banyak menggunakan media gambardikhawatirkan para peserta didik kurang terfokus.

d. Siswa sulit dikontrol apakah benar ia memperhatikan materi atau hanya melihat media yang digunakan.

e. Sebagian besar kelas l.ain terganggu karna adanya suara dari media yang digunakan.

f. Memerlukan kesiapan dan perencanaan disamping memerlukan waktu yang cukup panjang, yang mungkin terpaksa mengambil waktu atau jam pelajaran lain.

g. Memerlukan keterampilan guru secara khusus.

\section{G. MEDIA PEMBELAJARAN DALAM PENDIDIKAN MATEMATIKA}

Berikut beberapa media pembelajaran yang dapat digunakan dalam pendidikan matematika:

1. Media Komik Pada Pembelajaran Matematika(Nugraheni, 2017). 
Rasiman dan Siska (2014) menjelaskan bahwa penggunaan media komik dalam pembelajaran matematika dapat meningkatkan minat baca siswa, berpikir kritis, dan menanamkan nilai karakter yang positif. Penelitian yang dilakukan oleh Sastra Negara (2014) menyimpulkan bahwa penggunaan media komik cukup dapat memotivasi siswa dalam belajar sehingga kesan negatif siswa terhadap pelajaran matematika yang sulit dan tidak menyenangkan bahkan sebagai momok dalam pembelajaran dapat dihilangkan berubah menjadi pelajaran matematika yang menyenangkan sehingga berakibat minat dan antusias belajar siswa menjadi meningkat yang akhirnya bermuara pada peningkatan hasil belajar matematika siswa. Penggunaan media komik ini juga dapat dipadukan pada modelmodel pembelajaran sebagai sentuhan atau pewarna dalam proses pembelajaran dan juga dapat diselingi dengan permainan matematika. Kita sebagai guru juga dapat menanamkan nilai- nilai karakter yang baik dalam cerita tokoh-tokoh komik yang kita buat.

2. Media Macromedia Flash Pada Pembelajaran Matematika (Masykur et al., 2017)

Penggunaan macromedia flash sebagai media pembelajaran, bermanfaat bagi guru sebagai alat bantu dalam menyiapkan bahan ajar dan menyelenggarakan pembelajaran. Media ini juga dapat memancing stimulus siswa agar dapat memanipulasi konsep-konsep serta dapat mengetahui bentuk nyata konsep matematika yang abstrak (Yudi , 2016).

3. Media Animasi Dengan Aplikasi Video Maker Fx Pada Pembelajaran Matematika(Arlovi \& Astutik, 2013)

Video Maker FX merupakan aplikasi pembuat animasi dan berfungsi sebagai promosi dari bidang bisnis. Aplikasi Video Maker FX dapat membantu seseorang untuk membuat media animasi atau motion graphic dengan lebih mudah tanpa membutuhkan keahlian khusus. Pemanfaatan media pembelajaran dalam dunia teknologi dan informasi harus terus dikembangkan oleh para guru agar dapat bersaing pada era modern seperti saat ini.

4. Model Team Assisted Individualization (TAI) Terhadap Kemampuan Berpikir Kritis Matematis Siswa Berbasis Media Whatsapp(Nurhikmah \& Ernawati, 2020)

Model pembelajaran kooperatif tipe Team Assisted Individualization (TAI) merupakan model yang mengkombinasikan keunggulan pembelajaran kooperatif dan pembelajaran individual, Sehingga pada masa pandemi sekarang Aplikasi Whatsapp bisa dijadikan media pembelajaran dalam kelas daring. 
5. Media Pembelajaran Menggunakan Aplikasi Edmodo(Mytra et al., 2020)

Salah satu aplikasi pada internet yang bisa digunakan untuk e-learning adalah Edmodo. Edmodo adalah sebuah platform pembelajaran sosial untuk guru/dosen, siswa/mahasiswa maupun untuk orang tua/wali yang dikembangkan pada akhir 2008 oleh Nic Borg dan Jeff O’Hara. Dengan media edmodo mahasiswa dapat dikontol secara berkelanjutan oleh orang tua dengan adanya akun kontrol yang terhubung kepada orang tua mahasiswa.

\section{A. KESIMPULAN:}

Berdasarkan pembahasan diatas dapat disimpulkan :

1. Pembelajaran adalah proses interaksi antara poeserta didik dan sumber belajar pada satu lingkungan belajar. Pembelajaran merupakan proses yang diberikan oleh pendidik agar dapat memiliki pengetahuan, penguasaan dan kemahiran serta dapat membentuk sikap sikap dan kepercayaan diri pada pesert didik.

2. Pembelajaran matematika merupakan serangkaian aktivitas guru dalam memberikan pengajaran terhadap siswa untuk membangun konsep-konsep dengan kemampuan sendiri, sehingga konsep tersebut terbangun dengan pendekatan atau metode mengajar dalam meningkatkan kompetensi dasar.

3. Dalam pelaksanaa proses belajar mengajar harus memperhatikan beberapa hal, seperti berikut:
a. Tujuan pembelajaran yang akan dicapai.
b. Isi materi pelajaran.
c. Strategi belajar mengajar yang digunakan.
d. Karakteristik siswa yang belajar.

4. Media pembelajaran yang bisa digunakan pada pendidikan matematika, berikut ini beberapa yang bisa digunakan :
a. Media Komik Pada Pembelajaran Matematika
b. Media Macromedia Flash Pada Pembelajaran Matematika
c. Media Animasi Dengan Aplikasi Video Maker Fx Pada Pembelajaran Matematika
d. Media Whatsapp 
e. Media Pembelajaran Menggunakan Aplikasi Edmodo

B. Saran :

Saya sebagai manusia biasa di bidang pendidikan dan belum mendapatkan apapun selain rasa lelah dan capek ketika mendapatkan tugas dari dosen, kiranya para pembaca bisa memberikan saran agar bisa saya jadikan sebagai dorongan untuk menjalani hidup dengan lebih baik. Kirim saran via email lutfiy.brown@gmail.com. Rasa syukur untuk kehidupan dan berusaha untuk berubah adalah sukses mencapai kebahagian.

\section{DAFTAR PUSTAKA}

Arlovi, A. R., \& Astutik, H. S. (2013). PENGEMBANGAN MEDIA PEMBELAJARAN ANIMASI MATEMATIKA MELALUI PENERAPAN APLIKASI VIDEO MAKER FX PADA PEMBELAJARAN MATEMATIKA. Journal of Chemical Information and Modeling.

Irmayanti, Islamiah, N., \& Syarifuddin. (2020). Analisis sosiomatematika berbasis kearifan lokal dalam pembelajaran pada siswa sdn 224 palae.

Masykur, R., Nofrizal, \& Syazali, M. (2017). Pengembangan Media Pembelajaran Matematika dengan Macromedia Flash.

Mytra, P., Arsyad, M., \& Heriyanti, A. (2020). KEPRAKTISAN PEMBELAJARAN MENGGUNAKNAN APLIKASI EDMODO.

Mytra, P., \& Heriyanti, A. (2000). DESKRIPSI PEMAHAMAN MATERI PECAHAN SISWA KELAS VII SMP NEGERI 1 SALOMEKKO.

Netriwati, \& Lena, M. S. (2019). Media pembelajaran matematika.

Nugraheni, N. (2017). PENERAPAN MEDIA KOMIK PADA PEMBELAJARAN MATEMATIKA.

Nurhikmah, \& Ernawati. (2020). Pengaruh model team assisted individualization (tai) terhadap kemampuan berpikir kritis matematis siswa berbasis media whatsapp.

Nurjannah. (2020). PROSES BERPIKIR KREATIF SISWA SMP BERDASARKAN TAHAPAN WALLAS DALAM MEMECAHKAN MASALAH MATEMATIKA DITINJAU DARI ADVERSITY QUOTIENT (AQ). 
Sadiman, Arief S.(2005) Media pendidikan pengertian, Pen-gembangannya dan Pemanfaatnya Sudjana, Nana . (2007). Teknologi Pengajaran 